\title{
Formability and surface quality of non-conventional material sheets for the manufacture of highly customized components
}

\author{
Antonio Formisano ${ }^{1}$ (D) Antonello Astarita ${ }^{1}$ (D) $\cdot$ Luca Boccarusso $^{1}$ (D) $\cdot$ Marco Garlasché $^{2}$ (D) Massimo Durante ${ }^{1}$ (D)
}

Received: 12 November 2021 / Accepted: 2 February 2022 / Published online: 1 March 2022

(c) The Author(s) 2022, corrected publication 2022

\begin{abstract}
In this work, incremental forming of pure niobium planar isotropic sheets was studied; in particular, two different types of test were conducted by varying the tool/sheet contact conditions, in order to understand the complex phenomena interesting this hard-to-form non-conventional material and to focus the attention on its formability and the finishing of the worked surfaces. From the tests, the formability limits were determined, the forming forces were acquired and analysed, the quality of the worked surfaces was evaluated with measures of roughness and high-magnification visual inspection, as well as the failures of the sheets were observed and interpreted. The results highlight that a proper choice of the contact conditions can avoid the occurrence of galling while preserving an optimal carrying out of the process. In any case, very good surface finishing and workability of niobium sheets, despite their brittle nature, is found when incrementally formed. As a consequence, incremental sheet forming of this non-conventional material can be considered a faisible way of manufacturing highly customized components.
\end{abstract}

Keywords Incremental forming $\cdot$ Niobium $\cdot$ Contact conditions $\cdot$ Sheet metal formability $\cdot$ Wear

\section{Introduction}

Single point incremental forming (SPIF), i.e. the basic version of the incremental forming process requiring no dies and forming tools with simple shapes [1], is being extensively used as an alternative technique in sheet metal industry operations for the manufacture of components with symmetric and asymmetric shapes by using CNC machines [2].

Massimo Durante

mdurante@unina.it

Antonio Formisano

aformisa@unina.it

Antonello Astarita

antonello.astarita@unina.it

Luca Boccarusso

luca.boccarusso@unina.it

Marco Garlasché

marco.garlasche@cern.ch

1 Department of Chemical, Materials and Production Engineering, University of Naples Federico II, Naples, Italy

2 CERN - European Centre for Nuclear Research, Geneva, Switzerland
This process, initially developed for the needs of car body manufacturers, is now used in many other industries, i.e., automotive, aerospace, marine and medical [3]; in addition, thanks to its high flexibility, SPIF is also considered as a viable solution for reshaping sheet metal End-of-Life components, in line with the principles of the circular economy [4].

In this process, the main parameters, namely the tool/ sheet contact conditions (tool diameter, tool shape, use of lubricants, surface treatments, etc) and the tool path strategy (geometry, incremental step, feed rate, etc) are set to incrementally form sheets of pure metals, alloys, polymers and composites for the production of parts in fields requiring the production of customized components in a short time and at low cost.

The investigation of the tool/sheet contact conditions represents a very interesting topic when forming metals: for example, the choice of the lubricants affects the hardness of AA1100 incrementally formed components [5]; moreover, the formability of AA2024-O sheets can be increased through an opportune combination of shape and dimension of the forming tool [6].

All the more reason, this investigation is unavoidable for hard-to-form materials, like magnesium, titanium and their 
alloys [7]. Concerning this, a study on the warm incremental forming of AZ31 sheets demonstrated the necessity of developing lubricating method to give good solid lubrication performance and surface quality of components made of this magnesium alloy; furthermore, a previous authors' work highlighted that the formability limits of grade 1 titanium sheets can be improved by means of a thermal oxidation treatment of the worked surfaces [8].

Staying in theme of engineering materials, during the last decades, niobium $(\mathrm{Nb})$ and its alloys are getting growing attention due to some intriguing properties: high room temperature ductility and melting temperature, exceptional strength at high temperatures and low thermal neutron absorption cross section; moreover, $\mathrm{Nb}$ exhibits the lowest density in the family of refractory materials [9]. What is more, $\mathrm{Nb}$ shows, among the superconductive elements, both the highest lower critical magnetic field (HC1) [10] and superconducting transition temperature [11], as well as a high normal state thermal conductivity [12].

Thanks to these properties, high purity $\mathrm{Nb}$ is used for the fabrication of superconducting radiofrequency (SCRF) accelerating cavities [13], superconducting sheets [14], pressure tubes for nuclear reactors and the chemical process industry [15] and so on [16]. Among these applications, the production of SCRF cavities is probably the most challenging and intriguing. Their performances are sensitive to the $\mathrm{Nb}$ chemical and physical properties as well as the microstructure, so much that a well defined and controlled processing route must be used to fabricate these components. Traditionally, these components were produced joining, by electron beam welding, sub-components obtained by deep drawing; but freshly, because of the request of more powerful accelerators, new production processes for manufacturing high performances cavities are considered, like explosive forming, tube hydroforming, spinning of deep drawn or spun tubes and combined process (e.g. swaging and tube hydroforming) [17]. It is also interesting to recall that this kind of product, the SCRF cavities, is fabricated in extremely small batches (sometimes only one cavity for each batch); so, to design a proper processing route and to ensure the high properties required, it is mandatory to understand the behaviour of the material and to develop reliable constitutive and mathematical models [18].

Coupled with the above mentioned intriguing and unique properties, $\mathrm{Nb}$ also shows some peculiar behaviours that need to be understood to design the processing routes properly. In fact, it was proved that aiming to ensure good formability, some aspects are of primary interest for $\mathrm{Nb}$ [19].

One of the main issues in forming of high purity $\mathrm{Nb}$ is its anisotropy that could undermine the achievement of symmetric and uniform cavities during deep drawing process. It was found that the anisotropy coefficient of high purity $\mathrm{Nb}$ decreases with the plastic strain and is also strongly influenced by the texture [20]. Kim et al. [21] obtained interesting insight on the plastic behaviour of $\mathrm{Nb}$ by studying the stress-strain curves by compression and tension of nanopillars; they observed that the compression curves present a number of discrete segments showing intermittent strain bursts, while the tension ones show reduced plasticity, with elongation at failure equal to $3 \%$. This suggests that $\mathrm{Nb}$ shows a kind of Portevin-Le Chatelier effect [22] under certain loading conditions, due to the pinning of the dislocations against preferential glide planes.

The complex role of dislocations in $\mathrm{Nb}$ forming and their interactions with the lattice were elucidated in [23]; they found that the processing conditions strongly influence the dislocation formations and, subsequently, the physical properties (which are of great deal of interest for high energy applications) of $\mathrm{Nb}$ parts.

Kommel [24] observed that severe plastic deformation reduces the electrical conductivity of $\mathrm{Nb}$, suggesting that the dislocations obstacle the movement of the electron. They also observed a softening of the material and a decrease of the Young modulus when the strain rate increases during plastic deformation; this outcome was explained by Kommel et al. [25] on the basis of the interatomic attraction forces in the lattice.

Surface finishing is also a primary requirement in the SCRF cavities; a perfect mirror-like surface is required to ensure the proper behaviour of the cavities when in service [26]. Nb presents unusual surface properties; for example, when the grain size is small and uniform, it ensures good formability and circumvents, after a deep drawing process, too high surface roughness (resulting in an orange peel effect), as a consequence of the non-uniform deformation of large grains showing different crystalline orientation [27]. Consequently, a prediction of the surface finishing results difficult [28], as well as of the friction coefficient to set in equations for the process modelling [29].

Bringing together all the discussed literature, three point can be of particular interest for this work: i) the fabrication of components like SRCF cavities is a small batch/high variability production process; ii) $\mathrm{Nb}$ has good formability, but the pronounced anisotropic behaviour can lead to inhomogeneities in the formed part; iii) a poor tribological behaviour of $\mathrm{Nb}$ is observed, so to ensure the desired surface finishing particular attention must be paid during the forming process. On these premises, it can be interesting to investigate the incremental forming of planar isotropic $\mathrm{Nb}$ sheets: first of all, this forming process is particularly prone to high variability-small batch production [30]; secondly, the tool/sheet contact conditions can be tailored to achieve the desired surface finishing [31].

In a previous work [32], the authors highlighted the strong influence of the tool/sheet contact conditions and the importance of their choice for a correct carrying out of 
the incremental sheet forming of $\mathrm{Nb}$ parts; these considerations were made in light of an experimental campaign by using one only forming tool type (a hemispherical tipped tool) and one only shape of the components (fixed slope angle cone frusta).

The scope of this paper is to increase understanding related to the incremental forming of planar isotropic $\mathrm{Nb}$ sheets, taking into account further tool/sheet contact conditions and features; in detail, qualitative and quantitative evaluations of the formability limits, the forming forces and the roughness of the worked surfaces were made, as well as an interpretation of failures interesting the sheets. To this end, variable slope angle cone frusta and fixed slope angle square pyramid frusta were manufactured by SPIF, and the results from an experimental campaign on dry and lubricated sheets, formed with two different forming tools, were compared.

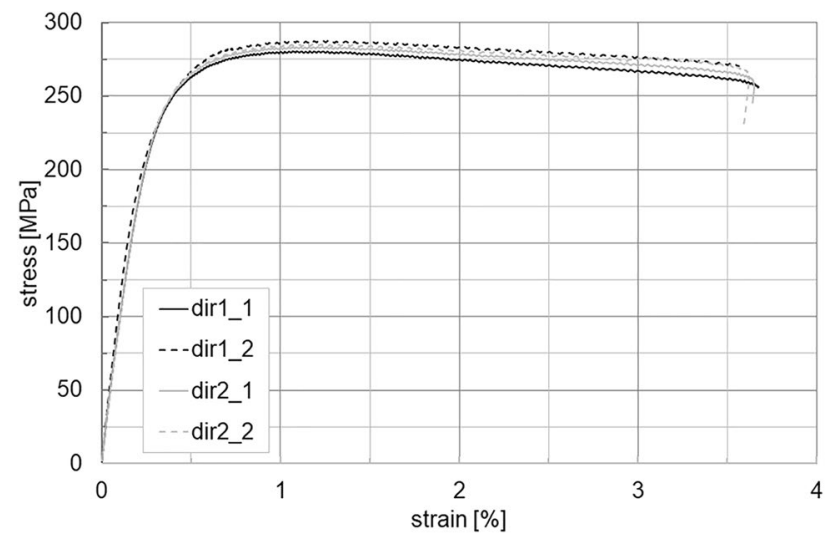

Fig. 1 Engineering stress-strain curves obtained through the tensile tests

Fig. 2 Scheme of the experimental setup adopted for the forming tests: clamped sheet and components of the forming forces

\section{Materials and methods}

Pure $\mathrm{Nb}$ rolled sheets, thick $t=0.5 \mathrm{~mm}$, were tested; their chemical composition is fully available in [33]. They were obtained by the cold-rolling of parent sheets $\left(t_{0}=3.0 \mathrm{~mm}\right.$ in thickness). The thickness reduction was performed by means of an electric flat rolling mill [34] along two directions, perpendicular to each other; it was obtained by many reduction steps, that alternate along the two directions, each of which equal to $r s=0.25 \mathrm{~mm}$. In this way, they can reach an almost planar isotropy; as a confirmation of this and of the reproducibility of the outcomes, you can see in Fig. 1 the engineering stress-strain curves from tensile tests carried out by using an MTS universal testing machine, following the ASTM E8 standard and along two mutually perpendicular directions (labelled as dir1 and dir2). A brittle behaviour can be highlighted (elongation at failure $\varepsilon_{f}=3.6 \%$ ); furthermore, a yield stress $Y=258 \mathrm{MPa}$, an ultimate tensile strength $U T S=283 \mathrm{MPa}$ and a Young modulus $E=107 \mathrm{GPa}$ are also measured.

The SPIF was carried out by means of a high speed vertical machining center C.B. Ferrari at room temperature. Pieces of sheets $\left(L_{s}^{2}=140 \times 140 \mathrm{~mm}^{2}\right)$ were clamped peripherally by a frame with an internal square area, $L_{f}=100 \mathrm{~mm}$ side. This last was fixed on the table of the $\mathrm{CNC}$ machine. A schematic of an incremental formed sheet and the clamping frame is reported in Fig. 2 (for the sake of drawing readability, only one half of the clamping frame is represented).

The influence of the tool/sheet interaction on the process was assessed planning tests in dry and lubricated conditions (for this last case, Reactolab industrial grease was used) and varying the forming tool: specifically, a hemispherical tipped tool and a roller-ball tool (a CAD model of which is reported in Fig. 3a and b, respectively) were used. They are both of stainless steel, with a diameter of $10 \mathrm{~mm}$, and were held by the CNC machine spindle. Different tests were carried out using the hemispherical tipped tool both in dry and lubricated conditions and the roller-ball tool in lubricated

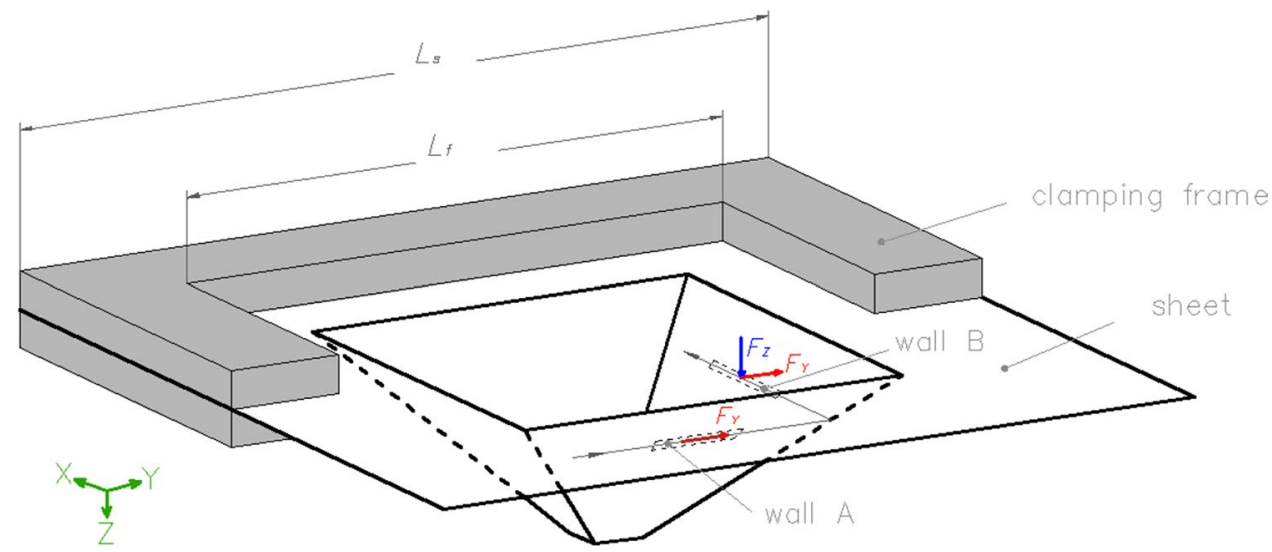


hemispherical tipped tool

\section{(a)}

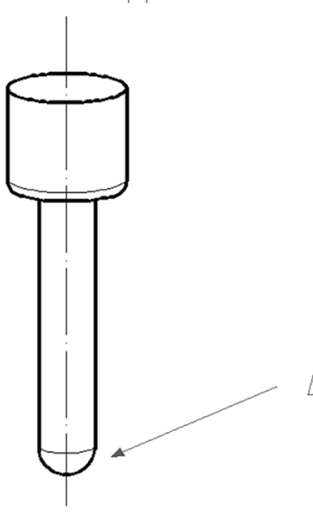

roller-ball tool

(b)

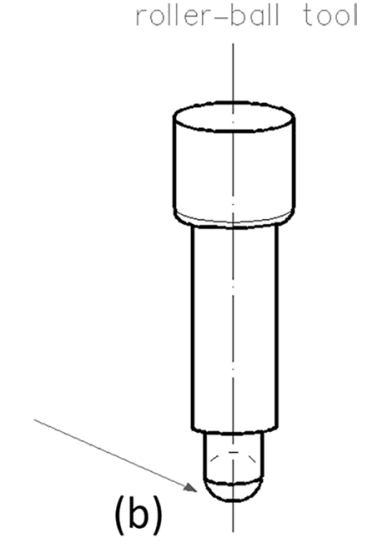

Fig. 3 CAD model of hemispherical tipped (a) and roller-ball tool (b) used in this experimentation

condition, in order to ensure the correct ball rolling in its housing. In the rest of the text, the three tool/sheet contact typologies are labelled as follows: HT (dry) for hemispherical tipped tool in dry condition, HT (grease) for hemispherical tipped tool in lubricated condition and RB for roller-ball tool in lubricated condition.

The experimental campaign involved the manufacture of two types of components: cone frusta with variable slope angle (variable slope angle tests) and square pyramid frusta with fixed slope angle (fixed slope angle tests), in a number of three for each contact condition. A CAD representation of the two geometries is reported in Fig. $4 \mathrm{a}$ and b, respectively (the representation of the two consecutive spirals of the tool path for the indication of the angular and vertical steps is not in scale, for the sake of drawing readability). All the components were obtained setting helical tool paths described at a feed rate $f=3000 \mathrm{~mm} / \mathrm{min}$, clockwise around the $\mathrm{z}$-axis in respect of the right hand rule.
Variable slope angle tests were performed to determine the influence of the contact conditions on the formability limits of the $\mathrm{Nb}$ sheets, in terms of maximum slope angle achievable on geometries (cone frusta) without geometrical singularities (like the ribs of pyramid frusta) and for which this feature increases continuously as the process progresses; in so doing, it is possible to investigate this feature in one only test, rather than a series of fixed slope angle tests with increasing angle. These destructive tests were carried out by following what was done by [35]: they ended to the onset of fractures; following this, the evaluation of the maximum slope angle $\left(\alpha_{\max }\right)$ was made by means of geometrical measures in correspondence with the failure z-position.

They state that the slope angle of the walls starts from an initial value $\alpha_{0}=45^{\circ}$ and the incremental angular step between two consecutive spirals of the tool path was $\alpha s=0.5^{\circ}$; in doing so, the components take the shape of a cone frustum, with the radius of the major base $R=35 \mathrm{~mm}$, and the lateral surface of a circular cylinder, with generatrix radius $R_{g}=50 \mathrm{~mm}$.

The fixed slope angle tests, for which an incremental vertical step between two consecutive spirals of the tool path $\mathrm{vs}=0.5 \mathrm{~mm}$ was chosen, were carried out to measure the forming forces and the quality of the worked surfaces. The components manufactured in these tests (side of the major base $L=70 \mathrm{~mm}$, slope angle $\alpha=60^{\circ}$ and height $h=39 \mathrm{~mm}$ ) present flat walls that allow easy acquisition of roughness; moreover, the straight lines of the tool paths along the walls allow to distinguish between the forces linked to the thrust of the forming tool on them and the ones linked to friction and flattening of the feed rate.

The measurement of the vertical component $\left(F_{Z}\right)$ and one only horizontal component $\left(F_{Y}\right)$ of the forming forces was carried out by means of a piezoelectric transducer (Kistler 9257A) completed with a NI 9239 input module and the
Fig. 4 CAD model of cone frustum with variable slope angle (c) and square pyramid frustum with fixed slope angle (d)
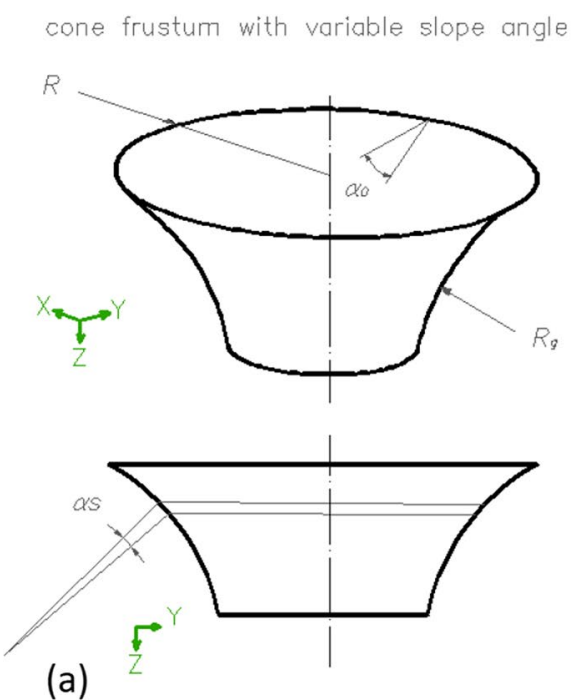

(a)

(b)
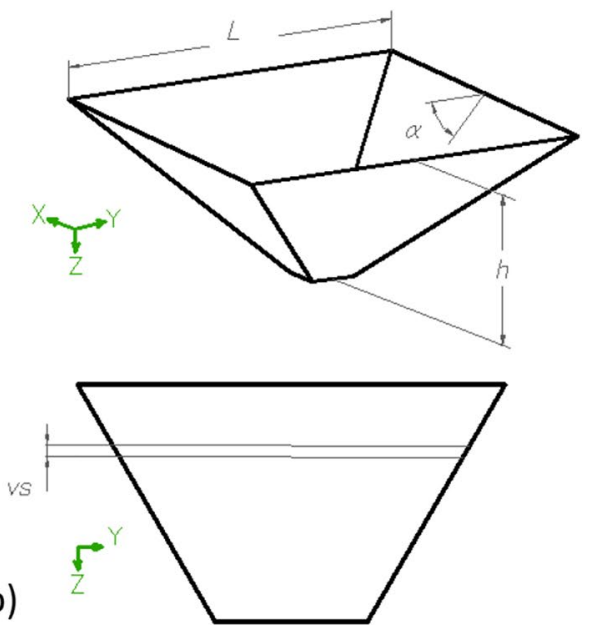
VBA 1.0 B software; the data were filtered following their acquisition at $2000 \mathrm{~Hz}$. Figure 2 schematizes these components on two adjacent walls of the frusta (labelled as A and $\mathrm{B}$ ).

A comparison in terms of forces was conducted in steadystate and far from the ribs, then only in the central area of the walls (in so doing, excluding the peaks that reveal the interaction of the tool with the ribs). Under the assumption of planar isotropy of the sheets, one only wall for each spiral of the tool path (in this work, the wall B was chosen) is enough to describe the vertical component of the forming force; on the contrary, two adjacent walls must be considered for the horizontal one (A and B; the other two show almost the same absolute values). In detail, for the wall A, the lines of the tool path and the horizontal channel of the acquisition system are parallel; this channel records a force from two contributes: the first one for flattening the sheet as a consequence of the vertical displacement and the second one lied to the friction between the tool and the sheet; concerning the wall $\mathrm{B}$, for which the lines of the tool path are perpendicular to the horizontal channel acquisition direction, the force is lied to the thrust on the pyramid walls [8].

The surface quality was assessed by high-magnification visual inspection and by measuring different linear roughness parameters along the cross-section of the worked surfaces, more specifically: the mean roughness $\left(R_{a}\right)$; the root mean square roughness $\left(R_{q}\right)$; the maximum height of the profile $\left(R_{y}\right)$; the mean roughness depth $\left(R_{z}\right)$. A Mitutoyo Surftest SJ-301 tester was used; five measurements for each contact condition, but also on undeformed sheets, were taken, following the ISO 4288 standard.

All relevant information about the experimental setting is summarized in Table 1 (equipment and tool/sheet contact conditions) and Table 2 (experimental setup).

\section{Results and discussion}

This section reports the main results from the experimental tests. In particular, the outcomes in terms of formability limits from the variable slope angle tests, and of forming forces and surface quality from the fixed slope angle tests were discussed, as well as an interpretation of the different sheet failures was done.

\section{Formability limits}

Figure 5a shows an example of variable slope angle test stopped at the failure occurrence (in correspondence of which $\alpha_{\max }$ was evaluated), in the specific for the HT (grease) condition; moreover, Fig. 5b reports the corresponding diagram of the vertical force, showing the reduced forces when the tool passes over the fractured parts.
Table 1 Equipment and tool/sheet contact conditions

\begin{tabular}{|c|c|}
\hline \multicolumn{2}{|l|}{ Sheet } \\
\hline Material & Niobium \\
\hline Behaviour & Planar isotropy \\
\hline Parent thickness, $t_{0}$ & $3 \mathrm{~mm}$ \\
\hline Reduction steps, rs & $0.25 \mathrm{~mm}$ \\
\hline Thickness, $t$ & $0.5 \mathrm{~mm}$ \\
\hline Area, $L_{s}^{2}$ & $140 \times 140 \mathrm{~mm}^{2}$ \\
\hline Young modulus, $E$ & $107 \mathrm{GPa}(\operatorname{dir} 1) ; 107 \mathrm{GPa}(\operatorname{dir} 2)$ \\
\hline Yield stress, $Y$ & $259 \mathrm{MPa}(\operatorname{dir} 1) ; 257 \mathrm{MPa}(\operatorname{dir} 2)$ \\
\hline Ultimate tensile strength, UTS & $282 \mathrm{MPa}(\operatorname{dir} 1) ; 279 \mathrm{MPa}(\operatorname{dir} 2)$ \\
\hline Elongation at failure, $\varepsilon_{f}$ & $3.60 \%(\operatorname{dir} 1) ; 3.61 \%(\operatorname{dir} 2)$ \\
\hline \multicolumn{2}{|l|}{ Forming tools } \\
\hline Material & Stainless steel \\
\hline Diameter & $10 \mathrm{~mm}$ \\
\hline Typologies & $\begin{array}{l}\text { Hemispherical tipped tool } \\
\text { Roller-ball tool }\end{array}$ \\
\hline \multicolumn{2}{|l|}{ Clamping frame } \\
\hline Internal area, $L_{f}^{2}$ & $100 \times 100 \mathrm{~mm}^{2}$ \\
\hline \multicolumn{2}{|l|}{ Lubricant } \\
\hline Description & Reactolab industrial grease \\
\hline \multicolumn{2}{|l|}{ Tool/sheet contact conditions } \\
\hline Typologies & $\begin{array}{l}\text { Hemispherical tipped tool/sheet in } \\
\text { dry condition, HT (dry) } \\
\text { Hemispherical tipped tool/sheet } \\
\text { in lubricated condition, HT } \\
\text { (grease) } \\
\text { Roller-ball tool/sheet in lubricated } \\
\text { condition, RB }\end{array}$ \\
\hline
\end{tabular}

From the variable slope angle tests, it is possible to affirm that the tribological aspects influence the formability limits; in fact, while $\alpha_{\max }$ values for HT (grease) and RB tests are practically the same $\left(74.7^{\circ}\right)$, for HT (dry) this feature decreases significantly $\left(\alpha_{\max }=64.7^{\circ}\right)$. Anyway, these values highlight significant incremental formability of the material tested; in fact the $\alpha_{\max }$ values are comparable with the ones of very ductile materials like, for example, AA7075 sheets tested in a similar way in a previous authors' work [36], even more so if considering the brittle behaviour of $\mathrm{Nb}$ highlighted by the tensile tests. This can be ascribable to the good response of the material to multiaxial stress and its strain rate sensitivity. Pan et al. [37] observed either flow softening or work hardening depending on the forming conditions, in particular they reported flow softening for all of the dynamic stress-strain curves. Still, for a given level of strain, the flow stress keeps growing with the deformation and does not show relevant saturation. This accounts for the observed strain rate sensitivity.

What is more, as recalled in the Introduction section, the formability of $\mathrm{Nb}$ is strongly influenced by the texturing and by some complex phenomena, i.e. the Portevin-Le Chatelier effect [22]; so, it is reasonable that different tribological 
Table 2 Experimental setup

\begin{tabular}{ll}
\hline Variable slope angle & \\
Component geometry & Cones with variable slope angle \\
Initial slope angle, $\alpha_{0}$ & $45^{\circ}$ \\
Angular step, $\alpha s$ & $0.5^{\circ}$ \\
Radius of the major base, $R$ & $35 \mathrm{~mm}$ \\
Generatrix radius, $R_{g}$ & $50 \mathrm{~mm}$ \\
Tool path characteristics: & \\
Geometry & Elical \\
Feed rate, $f$ & 3000 mm/min \\
Direction & Clockwise around the z-axis \\
Features analysed & Maximum slope angle, $\alpha_{\text {max }}$ \\
& Failures typologies \\
Fixed slope angle & \\
Component geometry & Pyramid frusta with fixed slope angle \\
Slope angle, $\alpha$ & $60^{\circ}$ \\
Vertical step, vs & 0.5 mm \\
Side of the major base, $L$ & 70 mm \\
Height, $h$ & 39 mm \\
Tool path characteristics: & \\
Geometry & Elical \\
Feed rate, $f$ & 3000 mm/min \\
Firection & Clockwise around the z-axis \\
& Vertical component of the forming forces, $F_{Z}$ \\
& Horizontal component of the forming forces, $F_{Y}$ \\
& Mean roughness, $R_{a}$ \\
& Maximum height of the profile, $R_{y}$ \\
& Root mean square roughness, $R_{q}$ \\
& Mean roughness depth, $R_{z}$ \\
& Morphos typologies \\
& \\
& \\
& \\
&
\end{tabular}

conditions will result in different deformation behaviour of the material. Looking at Fig. 5b, some oscillations can be seen; these oscillations can also be produced by the pinning of dislocations against the atoms of the lattice, as observed in previous work carried out on $\mathrm{Nb}$.

However, it is worth pointing out that with the variable slope angle tests there is an overestimation of the sheets formability compared to the maximum angles reachable with fixed slope angle tests. This discrepancy can be attributed to the process conditions of the fixed slope angle tests that are heavier; in fact, the angle does not start from lower values and, moreover, the presence of geometrical singularities like the ribs represents a critical issue [38].

In light of the considerations above reported on the formability limits, the slope angle chosen for the fixed slope angle tests (equal to $60^{\circ}$ ) was reasonably lower than the lower value of $\alpha_{\text {max }}$ recorded from the variable slope angle tests. The main results from these tests are reported in the following subsections. Another interesting result was the softening at high strain rate flow; this can be consequent to the rise of the adiabatic temperature, which usually occurs in viscoplastic materials subject to dynamic loading. Croteau et al. [39] in late 2020 published an interesting paper investigating the deformation behaviour of $\mathrm{Nb}$ single crystals and $\mathrm{Nb}$ sheets with a coarse grain size. They also observed a high strain rate softening and a marked anisotropic behaviour during deformation.

\section{Forming forces}

The steady-state condition of the forming forces was reached for all the tool/sheet contact conditions after a depth of about $5 \mathrm{~mm}$; by way of example, see Fig. 6 related to a HT (grease) fixed slope angle test. Contrary to the tests in lubricated conditions, carried out in a sound way up to the designed height, the HT (dry) tests failed after reaching the steadystate, for a height of about $15 \mathrm{~mm}$; consequently, they were prematurely stopped.

In light of above, the considerations on the forming forces were made for a $\mathrm{z}$-displacement between $5 \mathrm{~mm}$ (start of the steady-state) and $15 \mathrm{~mm}$ (failure occurrence for HT (dry) tests). Figure 7 shows the trends of the two components of the forming forces $\left(F_{Z}\right.$, Fig. 7a, and $F_{Y}$, Fig. 7b) in steadystate and at equal z-displacement $(\approx 8 \mathrm{~mm})$; you can note that $F_{Z}$, and $F_{Y}$ along wall B albeit on a smaller scale, are similar for all the contact conditions, with average values in the 




(a)

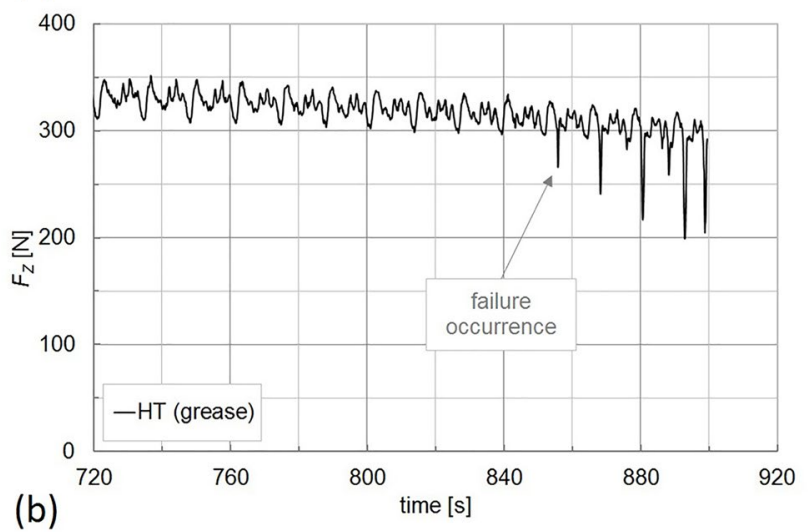

Fig. 5 HT (grease) variable slope angle test: failure occurrence (a) and force monitoring (b)

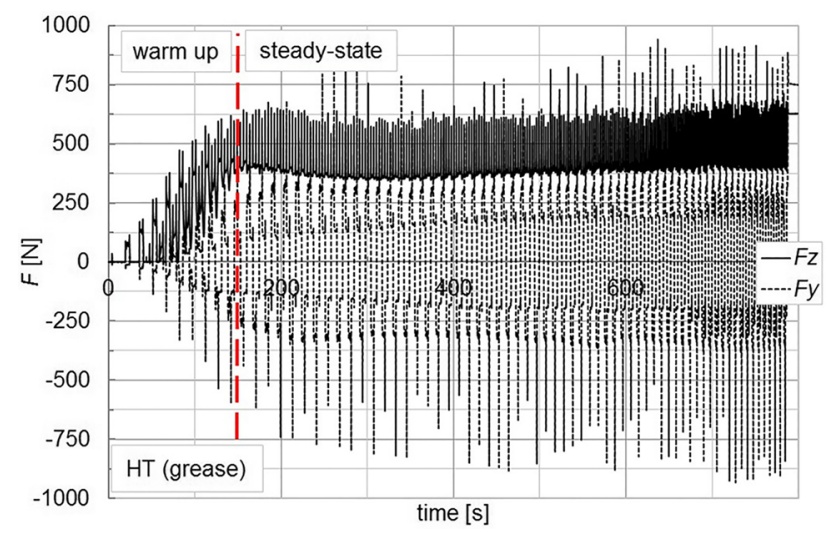

Fig. 6 Trend of the components of the forming forces during a HT (grease) fixed slope angle test

inspected area of about 370 and $85 \mathrm{~N}$, respectively. They are lied to the trust on the sheet and, then, to the designed geometry of the components; consequently, under the same slope angle and for similar shapes of the forming tools, significant differences for these components cannot be expected. The
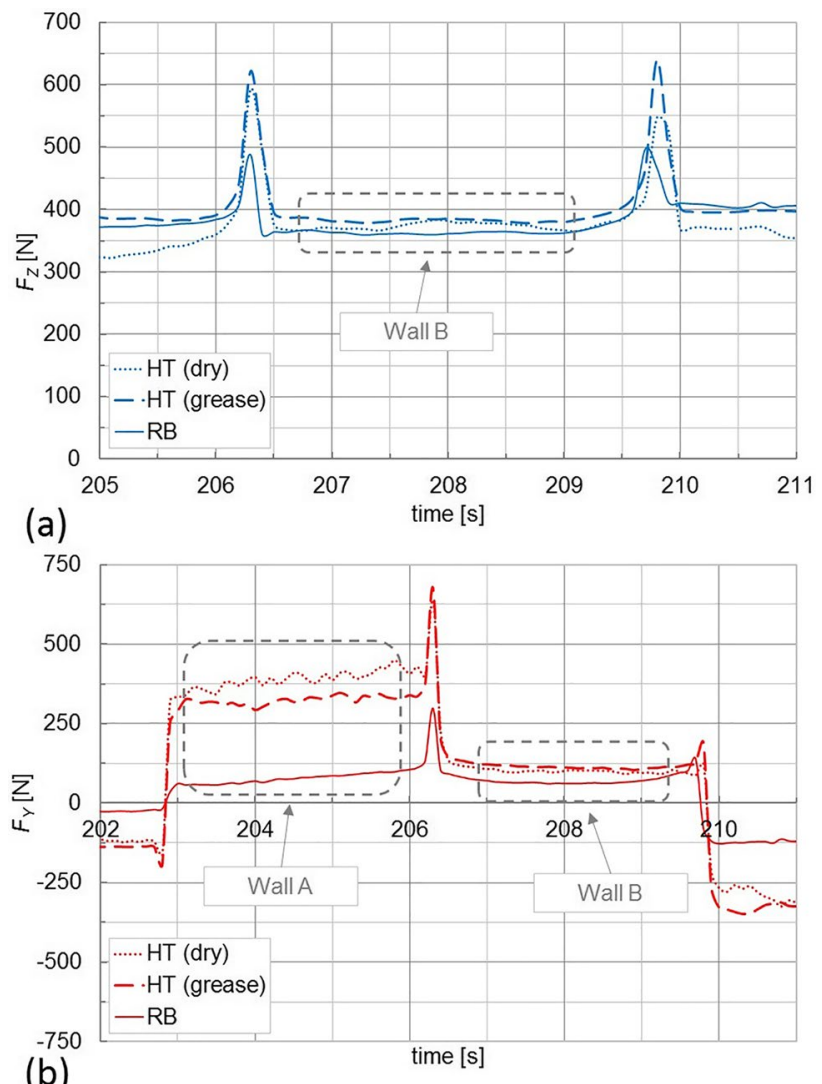

Fig. 7 Vertical (a) and horizontal component of the forming force (b) in steady-state of a fixed slope angle test

value of these components are influenced by the behaviour of tool and sheet and in particular, by assuming as rigid the tool, by the mechanical properties and the thickness of the sheet. On the other hand, $F_{Y}$ along wall $\mathrm{A}$ is influenced strongly by the tool/sheet contact conditions, so it results significantly lower under RB conditions (rolling friction; average value of about $80 \mathrm{~N}$ ); the other two conditions (sliding friction) not only determine significantly higher force values (in line with the considerations on the friction coefficients reported in [40]; average value of about $350 \mathrm{~N}$ ), but also show an irregular trend (in line with the results of a similar authors' study on another hard-to form material, i.e. the grade 1 titanium [8]), and both these aspects are more relevant for HT (dry) tests.

\section{Surface analysis}

Figure 8 reports some images of the worked surfaces for the different contact conditions, whereas Table 3 summarizes the mean values of the measured roughnesses (with the corresponding standard deviations between round brackets).

The use of the hemispherical tipped tool (Fig. 8a to c) involves a scratched surface as a consequence of the overlay 
Fig. 8 Wear (a) and failure (b) on a HT (dry) surface; wear on a HT (grease) (c) and a RB surface $(\mathbf{d})$

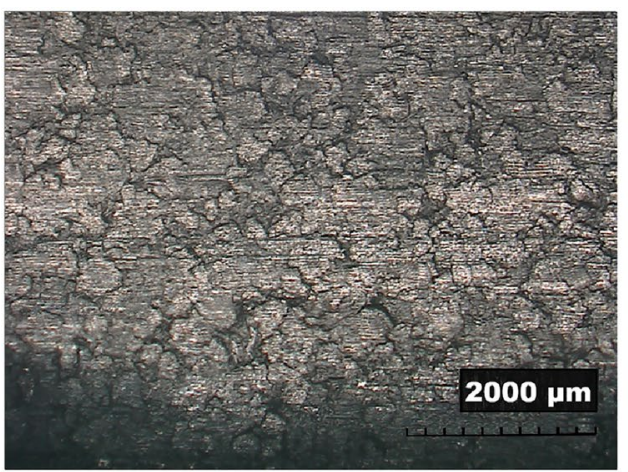

(a)

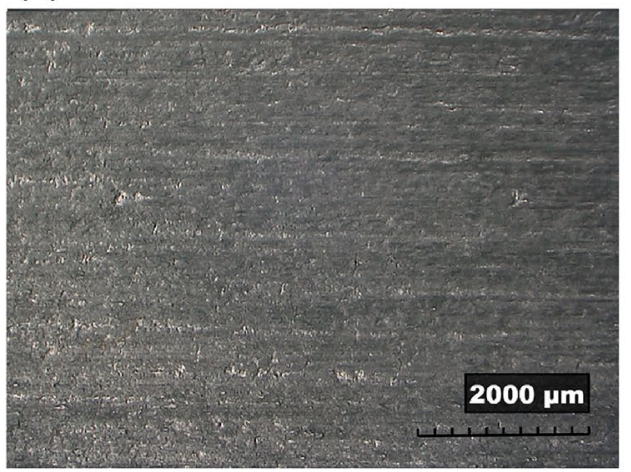

(c)

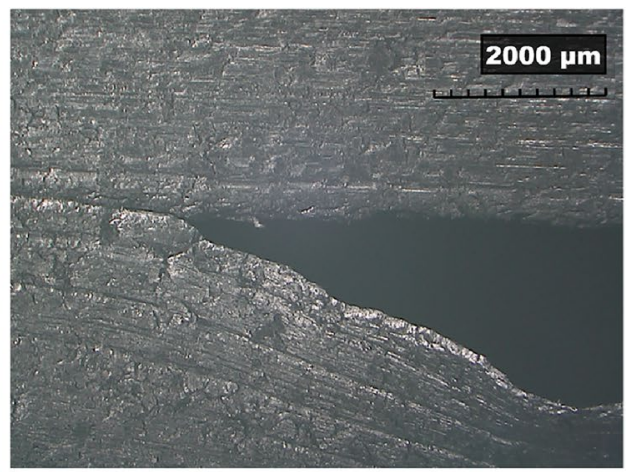

(b)

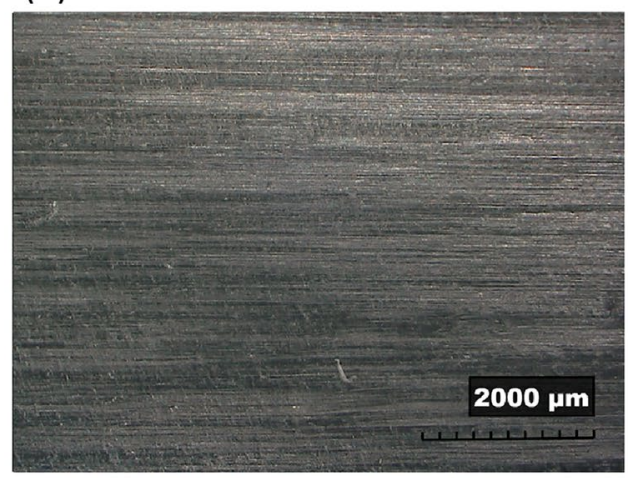

(d)
Table 3 Values of the roughness parameters

\begin{tabular}{lllll}
\hline $\begin{array}{l}\text { Contact condi- } \\
\text { tions }\end{array}$ & \multicolumn{5}{l}{ Roughness parameters $[\mu \mathrm{m}]$} \\
\cline { 2 - 5 } & $R_{a}$ & $R_{q}$ & $R_{y}$ & $R_{z}$ \\
\hline$H T($ dry) & $5.32(0.52)$ & $6.43(0.65)$ & $28.33(3.37)$ & $19.17(3.59)$ \\
$H T$ (grease) & $1.78(0.17)$ & $2.26(0.25)$ & $11.74(1.11)$ & $7.74(0.82)$ \\
$R B$ & $0.75(0.04)$ & $0.92(0.06)$ & $4.44(0.13)$ & $2.80(0.16)$ \\
Undeformed & $0.38(0.04)$ & $0.48(0.04)$ & $2.85(0.09)$ & $1.93(0.05)$ \\
\hline
\end{tabular}

of wear with the technological marks. In particular, the sheets are subject to the galling phenomenon; it represents a typology of adhesive wear, as the result of the macroscopic material transfer between metal surfaces, following their relative sliding motion [41]. As a consequence, the component of the forming force lied to the tool/sheet relative motion $\left(F_{Y}\right.$ along wall A, see Fig. $7 b$ ) results irregular; moreover, the sheets worked under HT (dry) conditions are strongly affected by galling, so as shown in Figure8a.

The inspection of the surfaces worked by the roller-ball tool (Fig. 8d) reveals that the adhesive wear is negligible, while the technological signatures that the forming tool leaves along its path are observable. As a consequence, the galling is not present for this working condition.

Table 3 confirms that there is a significant improvement of the quality going from using a hemispherical tapped tool in dry condition to a lubricated roller ball; in fact, the first solution shows values of the roughness parameters about seven times bigger, and more variable, than the corresponding ones of the second solution. Besides, this latter allows obtaining a slightly worse surface quality than the one of the undeformed sheets (with $R_{a}$ equal to 0.75 and $0.38 \mu \mathrm{m}$, respectively). In any case, all the working conditions guarantee $R_{a}$ values that, following the ISO 4287/1 standard, fall into the range typical of machined or hand grinded surfaces.

\section{Failures typologies}

As anticipated above, it is evident that the HT (dry) conditions are the most severe; in fact, they represent the only contact condition for which failures the fixed slope angle tests were not carried out in a sound way. Figure 9 shows the cracks occurring on the sheets from a HT (dry) fixed slope angle test. You can note that the failures interest not only a limited zone near the ribs, typical of incremental sheet forming of metals [42], but also other zones far from the ribs and subject to less severe work conditions (atypical failure; they occurred a few toolpath spirals before the occurrence of the typical failure). Besides, Fig. 8a highlights that these sheets are so much affected by galling that the scratches can condition the occurrence of failures (see Fig. 8b); concerning this, see the high $R_{y}$ and $R_{z}$ values reported in Table 3. This can limit the formability of the sheets, even more so if considering their small thickness and thinning resulting to 


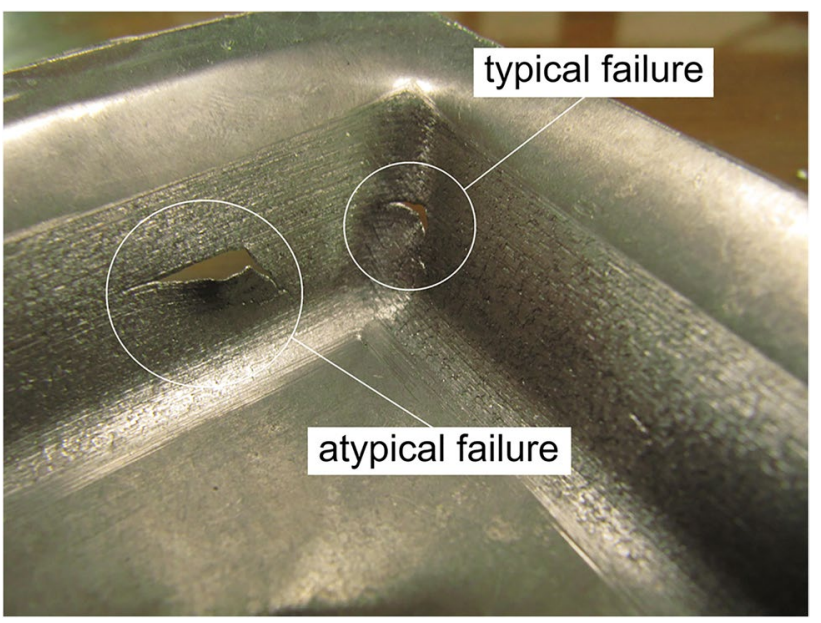

Fig. 9 Failures interesting a square pyramid frustum from an HT (dry) fixed slope angle test

the deformation process, presumably in agreement with the sine law [43].

On the contrary, by observing the failure that develops along a circumference going on the tool path from a HT (grease) variable slope angle test (see Fig. 5a), you can expect only typical metal sheet failures for the lubricated sheets [42].

\section{Conclusions}

The incremental forming of pure niobium thin rolled sheets with planar isotropic behaviour was investigated in this work. The experimental campaign included the production of variable slope angle cones and fixed slope angle pyramid frusta, obtained under different contact conditions: the process was conducted by using a hemispherical tipped tool both in dry and lubricated conditions and a roller-ball tool in lubricated condition; industrial grease was used as a lubricant.

The main results of the experimental campaign can be summarized as follows:

- The variable slope angle tests highlight that the sheets show very high workability when incrementally formed, similar to ductile metal alloys, despite their brittle behaviour under tensile tests. The formability limits are significantly lower in dry conditions (maximum slope angle of about $65^{\circ}$ ), while the tool type is not influential in lubricated conditions (maximum slope angle of about $75^{\circ}$ ). Moreover, this kind of test overestimates the formability limits, compared to the maximum angles reachable with fixed slope angle tests, especially in dry conditions;
- From the fixed slope angle tests, the tool/sheet contact conditions strongly influence the rate of forming force lied to friction. In detail, sliding friction when using the hemispherical tipped tool translates into significantly higher force values (with an irregular trend), even if in dry conditions, as a consequence of very high friction coefficients;

- The fixed slope angle tests also furnish information on the surface quality and the occurrence of failures. All the contact conditions guarantee very low roughness values of the worked surfaces, with the mean roughness always less than $6.0 \mu \mathrm{m}$, comparable to that obtained by machining or hand grinding. Despite this, sliding friction generates scratches as the effect of the galling. This adhesive wear phenomenon can limit the formability limits through the premature occurrence of failures in unexpected zones, but it can be strongly reduced by using the roller-ball tool.

The excellent formability of the sheets suggests, as future work, the proper investigation of their mechanical properties depending on the strain rate; this can be useful, along with the determination of the friction coefficient for the tool/sheet contact conditions typical of the incremental sheet forming, for correct implementation of numerical models in FE ambient.

Funding Open access funding provided by Università degli Studi di Napoli Federico II within the CRUI-CARE Agreement.

\section{Declarations}

Conflict of interest The authors declare that they have no conflict of interest.

Open Access This article is licensed under a Creative Commons Attribution 4.0 International License, which permits use, sharing, adaptation, distribution and reproduction in any medium or format, as long as you give appropriate credit to the original author(s) and the source, provide a link to the Creative Commons licence, and indicate if changes were made. The images or other third party material in this article are included in the article's Creative Commons licence, unless indicated otherwise in a credit line to the material. If material is not included in the article's Creative Commons licence and your intended use is not permitted by statutory regulation or exceeds the permitted use, you will need to obtain permission directly from the copyright holder. To view a copy of this licence, visit http://creativecommons.org/licenses/by/4.0/.

\section{References}

1. Duflou JR, Habraken AM, Cao J et al (2018) Single point incremental forming: state-of-the-art and prospects. Int J Mater Form 11:743-773. https://doi.org/10.1007/S12289-017-1387-Y

2. Behera AK, de Sousa RA, Ingarao G, Oleksik V (2017) Single point incremental forming: an assessment of the progress and 
technology trends from 2005 to 2015. J Manuf Process 27:37-62. https://doi.org/10.1016/J.JMAPRO.2017.03.014

3. Trzepieciński T, Oleksik V, Pepelnjak T et al (2021) Emerging Trends in Single Point Incremental Sheet Forming of Lightweight Metals. Met (11):1188. https://doi.org/10.3390/MET11081188

4. Zaheer O, Ingarao G, Lorenzo R, Di FL (2021, 2021) Understanding formability and geometrical accuracy of SPIF process used as Reshaping approach. ESAFORM. https://doi.org/10.25518/esafo rm21.4315

5. Najm SM, Paniti I, Viharos J (2020) Lubricants and affecting parameters on hardness in SPIF of AA1100 Aluminium. In: 17th IMEKO TC 10 and EUROLAB Virtual Conference "Global Trends in Testing, Diagnostics \& Inspection for 2030.” pp. 387-392

6. Kumar A, Gulati V, Kumar P et al (2019) Parametric effects on formability of AA2024-O aluminum alloy sheets in single point incremental forming. J Mater Res Technol 8:1461-1469. https:// doi.org/10.1016/J.JMRT.2018.11.001

7. Formisano A, Astarita A, Boccarusso L et al (2015) Formability evaluation of grade 1 titanium sheets depending on the temperature by FE analyses. Key Eng Mater 651-653:1054-1059. https://doi.org/10.4028/www.scientific.net/KEM.651-653.1054

8. Formisano A, Durante M, Boccarusso L, Astarita A (2017) The influence of thermal oxidation and tool-sheet contact conditions on the formability and the surface quality of incrementally formed grade 1 titanium thin sheets. Int J Adv Manuf Technol 93:3723-3732. https://doi.org/10.1007/s00170-017-0805-0

9. Tan K, Markovych S, Hu W et al (2021) Review of application and research based on cold spray coating materials. Aerosp Tech Technol 0:47-59. https://doi.org/10.32620/aktt.2021.1.05

10. Bieler TR, Wright NT, Pourboghrat F et al (2010) Physical and mechanical metallurgy of high purity $\mathrm{Nb}$ for accelerator cavities. Phys Rev Spec Top - Accel Beams 13. https://doi.org/10. 1103/PhysRevSTAB.13.031002

11. Zaytseva I, Abaloszew A, Camargo BC et al (2020) Upper critical field and superconductor-metal transition in ultrathin niobium films. Sci Rep 10:1-10. https://doi.org/10.1038/ s41598-020-75968-9

12. Ermakov A, Jelezov I, Singer X et al (2008) Physical properties and structure of large grain/single crystal niobium for superconducting RF cavities. J Phys Conf Ser 97:012014. https://doi.org/ 10.1088/1742-6596/97/1/012014

13. Rathore M, Kumar Jain V, Atulkar A et al (2020) Study of Lorentz force detuning and its compensation in superconducting radiofrequency cavity: a review. Mater Today Proc. https://doi. org/10.1016/j.matpr.2020.11.506

14. Singh N, Deo MN, Roy SB (2016) Possible influence of surface oxides on the optical response of high-purity niobium material used in the fabrication of superconducting radio frequency cavity. Nucl Instruments Methods Phys Res Sect A Accel Spectrometers, Detect Assoc Equip 830:59-66. https://doi.org/10. 1016/j.nima.2016.05.060

15. Balat-Pichelin M, Sans JL, Escape C, Combes H (2017) Emissivity of Elgiloy and pure niobium at high temperature for the solar orbiter mission. Vacuum 142:87-95. https://doi.org/10. 1016/j.vacuum.2017.05.012

16. Aimone P, Yang M (2018) Niobium alloys for the chemical process industry. Int J Refract Met Hard Mater 71:335-339. https://doi.org/10.1016/j.ijrmhm.2017.11.036

17. Zamiri A, Pourboghrat F (2007) Characterization and development of an evolutionary yield function for the superconducting niobium sheet. Int J Solids Struct 44:8627-8647. https://doi.org/ 10.1016/j.ijsolstr.2007.06.025

18. Tennant C, Carpenter A, Powers T et al (2020) Superconducting radio-frequency cavity fault classification using machine learning at Jefferson Laboratory. Phys Rev Accel Beams 23:114601. https://doi.org/10.1103/PhysRevAccelBeams.23. 114601

19. Asensio J, Romano G, Martinez VJ et al (2001) Ferritic steels - optimization of hot-rolled textures through cold rolling and annealing. Mater Charact 47:119-127. https://doi.org/10.1016/ S1044-5803(01)00160-7

20. Ding R, Jones IP (2008) Mechanical properties and deformation behaviour of a niobium alloy with different carbon contents. Mater Sci Eng A 497:301-308. https://doi.org/10.1016/j.msea. 2008.07.038

21. Kim JY, Jang D, Greer JR (2009) Insight into the deformation behavior of niobium single crystals under uniaxial compression and tension at the nanoscale. Scr Mater 61:300-303. https://doi. org/10.1016/j.scriptamat.2009.04.012

22. Astarita A, Liberini M, Velotti C, et al (2016) Experimental study of the Portevin-Le Chatelier effect in AA 5754 sheets: influence of the different rolling routes. In: AIP Conference Proceedings. American Institute of Physics Inc., p 130007

23. Omranpour B, Kommel L, Mikli V et al (2019) Nanostructure development in refractory metals: ECAP processing of niobium and tantalum using indirect-extrusion technique. Int J Refract Met Hard Mater 79:1-9. https://doi.org/10.1016/j.ijrmhm.2018.10.018

24. Kommel L (2019) Microstructure and properties that change during hard cyclic visco-plastic deformation of bulk high purity niobium. Int J Refract Met Hard Mater 79:10-17. https://doi.org/ 10.1016/j.ijrmhm.2018.10.009

25. Kommel L, Kimmari E, Saarna M, Viljus M (2013) Processing and properties of bulk ultrafine-grained pure niobium. In: Journal of Materials Science Springer, pp. 4723-4729

26. Olsson M, Persson H, Bushlya V, Ståhl J-E (2018) Surface roughness and sub-surface deformation measurements in machining of niobium. Procedia CIRP 71:413-417. https://doi.org/10.1016/j. procir.2018.05.058

27. Kneisel P, Ciovati G, Dhakal P et al (2015) Review of ingot niobium as a material for superconducting radiofrequency accelerating cavities. Nucl Instruments Methods Phys Res Sect A Accel Spectrometers, Detect Assoc Equip 774:133-150. https://doi.org/ 10.1016/j.nima.2014.11.083

28. Gao C, Ma Y, Zhi TL et al (2017) Microstructural evolution and mechanical behavior of friction spot welded 2198-T8 Al-li alloy during aging treatment. Mater Des 115:224-230. https://doi.org/ 10.1016/j.matdes.2016.11.045

29. Khun NW, Frankel GS, Sumption M (2014) Effects of Normal load, sliding speed, and surface roughness on Tribological properties of niobium under dry and wet conditions. Tribol Trans 57:944-954. https://doi.org/10.1080/10402004.2014.927546

30. Linnemann M, Psyk V, Djakow E et al (2019) High-speed incremental forming - new technologies for flexible production of sheet metal parts. Procedia Manuf 27:21-26. https://doi.org/10.1016/j. promfg.2018.12.038

31. Gandla PK, Inturi V, Kurra S, Radhika S (2020) Evaluation of surface roughness in incremental forming using image processing based methods. Measurement 164:108055. https://doi.org/10. 1016/J.MEASUREMENT.2020.108055

32. Formisano A, Astarita A, Boccarusso L, et al (2021) Considerations on the influence of the tool/sheet contact conditions for incremental forming of niobium sheets. In: ESAFORM 2021 - 24th International Conference on Material Forming. PoPuPS (University of Liège Library)

33. Gallifa Terricabras A, Amorim Carvalho A, Aviles Santillana I, et al (2019) Assessment of the mechanical properties of ultra-high purity niobium after cold work and heat treatment with the HLLHC crab cavities as benchmark. In: 19th international conference on RF superconductivity (SRF 2019) proceedings. Pp 862-867 
34. Durante M, Formisano A, Boccarusso L, Langella A (2020) Influence of cold-rolling on incremental sheet forming of polycarbonate. Mater Manuf Process 35:328-336. https://doi.org/10.1080/ 10426914.2020.1726946

35. Hussain G, Gao L, Hayat N, Ziran X (2009) A new formability indicator in single point incremental forming. J Mater Process Technol 209:4237-4242. https://doi.org/10.1016/J.JMATP ROTEC.2008.11.024

36. Durante M, Formisano A, Langella A (2011) Observations on the influence of tool-sheet contact conditions on an incremental forming process. J Mater Eng Perform 20:941-946. https://doi. org/10.1007/s11665-010-9742-X

37. Pan Z, Xu F, Mathaudhu SN et al (2012) Microstructural evolution and mechanical properties of niobium processed by equal channel angular extrusion up to 24 passes. Acta Mater 60:2310-2323. https://doi.org/10.1016/j.actamat.2011.12.019

38. Durante M, Formisano A, Lambiase F (2019) Formability of polycarbonate sheets in single-point incremental forming. Int $\mathrm{J}$ Adv Manuf Technol 102:2049-2062. https://doi.org/10.1007/ s00170-019-03298-w

39. Croteau JF, Pai Kulyadi E, Kale C et al (2020) Effect of strain rate on tensile mechanical properties of high-purity niobium single crystals for SRF applications. Mater Sci Eng A 797:140258. https://doi.org/10.1016/j.msea.2020.140258

40. Silvestri AT, Astarita A, Boccarusso L et al (2020) Understanding the friction behavior of niobium sheets during forming processes. J Mater Eng Perform 29:3055-3066. https://doi.org/10. 1007/s11665-020-04868-w

41. Kakulite KK, Kandasubramanian B (2019) Rudiment of 'galling: Tribological phenomenon' for engineering components in aggregate with the advancement in functioning of the anti-galling coatings. Surfaces and Interfaces 17

42. Gatea $\mathrm{S}, \mathrm{Ou} \mathrm{H}$, Mccartney $\mathrm{G}$ Review on the influence of process parameters in incremental sheet forming. Int J Adv Manuf Technol. https://doi.org/10.1007/s00170-016-8426-6

43. Hussain G, Gao L, Zhang ZY (2008) Formability evaluation of a pure titanium sheet in the cold incremental forming process. Int J Adv Manuf Technol 37:920-926. https://doi.org/10.1007/ s00170-007-1043-7

Publisher's note Springer Nature remains neutral with regard to jurisdictional claims in published maps and institutional affiliations. 